\title{
Examining the Relationship Between School Mindfulness and Organizational Trust
}

\author{
Erkan Tabancal ${ }^{1} \&$ Gülay Öngel ${ }^{2}$ \\ ${ }^{1}$ Department of Educational Administration, Yıldız Technical University, Istanbul, Turkey \\ ${ }^{2}$ Şehit Batuhan Ergin Anatolian High School, Istanbul, Turkey \\ Correspondence: Gülay Öngel, Şehit Batuhan Ergin Anatolian High School, Istanbul, Turkey.
}

\author{
Received: January 6, $2020 \quad$ Accepted: February 17, $2020 \quad$ Online Published: May 24, 2020 \\ doi:10.5539/ies.v13n6p14 \\ URL: https://doi.org/10.5539/ies.v13n6p14
}

\begin{abstract}
The purpose of the study is to investigate the relationship between organizational trust and school mindfulness. To achieve this purpose, a quantitative approach and relational design were preferred, and School Mindfulness Scale and Organizational Trust Scale were used as data collection tools. The study sample consisted of 495 participants working in public schools in İstanbul province. The data was evaluated using arithmetic mean, correlation and regression analysis. According to the results, trust in the principal and colleagues improves school mindfulness. Furthermore, trust in the principal increases the mindfulness of the school principal, while trust in colleagues enhances mindfulness among the faculty. It can therefore be said that school principals may prefer to strengthen organizational trust to increase the level of mindfulness within the school.
\end{abstract}

Keywords: organizational trust, mindfulness, school mindfulness, trust in the principal, trust

\section{Introduction}

\subsection{Introduce the Problem}

Individuals' thoughts, emotions and actions have an impact on the organization they work for (Brief \& Weiss, 2002). The mindfulness approach found a place for itself in management studies with a view to using humans' potential for the benefit of organizations (Dane, 2011). Mindfulness leaves aside the static world view and represents an approach that produces positive results which would confer an advantage over previous convictions and assumptions. Enabling one to focus on the present moment, to be open to novelties and to perceive the differences between situations, mindfulness allows us to test previous assumptions in new situations. It helps us understand that the perceived realities are just world views, and that world views are not objective, since they are affected by previous experiences. Thus, mindfulness offers individuals the opportunity to function better and be more creative by exceeding their usual cognitive limits (Langer \& Ngnoumen, 2017).

Mindfulness is defined as the act of developing a different point of view for every instance and creating new categories, actively processing the meaning and context of any situation (Langer, 1992). Mindfulness proposes to pay attention to the present moment without prejudices (Giluk, 2009) and carefully examine the perception processes (Bjurström, 2012). It enables individuals to constantly question the way they interpret events or situations, allowing them to go beyond their experiences and seek fitting solutions. Mindful interpretations allow us to gain the perspectives that lead to the development of the most appropriate assessments (Fiol \& O'Connor, 2003), which in turn allow us to better understand our fellow humans and our environment (Teasdal \& Chaskolsan, 2011). Organizations can change depending on their mindfulness as much as individuals can. In other words, an organization can be just as mindful as an individual. Individual mindfulness is a state of consciousness in which one constantly tests assumptions by searching for errors, since mindfulness requires being open to novelties and changing perspectives. The same event can be interpreted in many ways, and so mindful individuals seek diverse meanings and nuances. Furthermore, they avoid the state of sleepiness linked to routines and traps caused by the parochial worldview, trying to notice what is different and new (Hoy, Gage \& Tarter, 2006).

School is a heterogeneous work environment addressing complex interests and demands (Smith \& Larimer, 2004). Teachers obtain information from many resources in the school environment; new information, however, is not reflected in their behavior, as the teachers have been generally successful already without this new information. That is, they have been deceived by their habits. For this reason, they fall victim to unchanging categories and 
routines and have difficulty in breaking this stability and responding to a dynamic world with new methods (Hoy, Gage, \& Tarter, 2004). To understand what is happening in complex organizations, it is necessary to find ways to encourage collective senses using different, and most importantly, conflicting information, different opinions and various observations of the workforce (Gebauer, 2012). Mindfulness can play a key role at this point, since mindfulness in schools has a strong potential to increase our awareness of effective schools (Hoy, Gage, \& Tarter, 2006).

According to Weick and Stucliffe (2001), mindfulness can be an organizational qualification. In organizations, mindfulness can be improved through processes such as dealing with crises, being responsive to operations, avoiding simple interpretations, committing to overcoming difficulties, and valuing expertise. Hoy, Gage and Tarter (2004) adapted these five processes in a way that forms a conceptual framework for schools.

1) Sensitivity to operations: Routines and rules manage behaviours regardless of the existing situation, causing mindless actions (Langer \& Moldoveanu 2000). Rules, procedures and policies cause the emergence of fixed organizational habits in schools. As a result, schools become so mindless in daily activities that they become vulnerable to unexpected events (Scarbrough, 2005). The sensitivity of teachers and school principals to school operations means being closely tied to learning and teaching activities, which are the main function of schools. Being sensitive to school operations is also important in dealing with failures (Bauch, 2014). Sensitivity does not cover only operations, but interpersonal relations as well. It requires scanning for problems and a strong social interaction between teachers and principals (Ginn, 2014).

2) Preoccupation with failure is counterintuitive: Preoccupation with failure involves proactive and preventive analyses and assessments of events and situations (Ndubisi \& Al Shuridah, 2019). Organizational mindfulness encourages individuals to take aim at mistakes, improve opportunities, and approach problems as systematically occurring events rather than as individual cases (Mu \& Butler, 2012). Mindful schools therefore constantly scan for problems, since success brings certain slackness, whereas dealing with failures prevents that slackness (Hoy, Gage \&Tarter, 2004; Weick \& Sutcliffe, 2007).

3) Reluctance to simplify: Schools have complex and unpredictable structures (Hoy, 2002). School principals and teachers who do not generalize easily are reluctant to simplify while interpreting behaviors (Hoy, Gage \& Tarter, 2004; Bauch, 2014). Paying adequate attention to events or situations instead of underestimating them helps us take control before they become more serious. In doing so, we not only prevent problems, but also notice hidden opportunities for change in advance (Mu \& Butler, 2009). The complex structure of schools requires school principals and teachers to develop multiple perspectives to understand the mysteries lying under those that are visible.

4) Commitment to resilience: Resilience to difficulties is about the attitude shown in the face of problems. Organizations cannot be freed from mistakes. Unexpected situations happen very often in organizational processes. Commitment to resilience requires employees to be strong and flexible when they encounter a problem. Finding someone to accuse when there is a problem is a characteristic of mindless organizations (Bauch, 2014). Mindful organizations, on the other hand, have the capacity to cope with crises and quickly recover from mistakes (Williamson, 2010).

5) Deference to expertise: Mindful schools try to avoid the mistake of adopting standard rules and rigid procedures. Instead, they use the expertise required to solve the problem. The decision-making process is collective. (Hoy, Gage \& Tarter, 2006; Ndubisi \& Al Shuridah, 2019). Commitment to expertise requires the use of expertise independently of hierarchy in case of a problem, since problems are solved with expertise, not with power. In mindful organizations, problems are solved by experts rather than people in certain departments or with certain roles (Bauch, 2014).

Mindfulness provides useful content in the working environment at both the individual and organizational level. Furthermore, it allows individuals to respond to environmental demands more efficiently (Valentine, Godkin, \& Varca, 2009); facilitates organizational change (Aviles \& Dent, 2015); optimizes work-related thoughts; reduces negative feelings and (Long \& Christian, 2015) automatic reactions (Long \& Christian, 2015; Glomb, Duffy, Bono, \& Yang, 2011; Roche, Haar, \& Luthans, 2014); increases quality (Ndubisi, 2012) and enables self-control (Wolf, Vykoukal, \& Beck, 2009). The study conducted by Yu and Zellmer-Bruhn (2017) shows that team mindfulness provides protection against multi-level conflicts. Studies show that supervisor mindfulness has a positive impact on organizational functioning and employee behavior, and that it may increase the employee performance and well-being as well as the administrator support perceived by employees and their sense of justice (Reb, Narayanan, \& Chaturvedi, 2014). Focusing on the present moment and being non-judgmental may enable leaders to pay attention to their followers and avoid hasty interpretations, unlocking mindful communication and 
allowing the leader to communicate more successfully (Arendt, Verdorfer, \& Kugler, 2019). According to Chaskolsan (2011), mindfulness can lead to a more efficient management and team. In their study, Kearney, Kelsey and Herrington (2013) concluded that students' academic success is related to mindfulness of school principals. Not only supervisors' but also employee's mindfulness benefits work activities. Mindful employees can be more conscientious about avoiding mistakes and being objective instead of being pessimistic and reactive to organizational changes (Hyland \& Mills, 2015). Mindfulness meets the employee's need for autonomy (Schultz, Ryan, Niemiec, Legate, \& Williams, 2014), increases the participation of employees in work processes (Malinowski \& Lim, 2015), and may lead to a more efficient communication form (Arendt, Verdorfer, \& Kugler, 2019). Additionally, it makes it easier for individuals to pay attention to serious stimulants in the work place and come to grips with performance-related mistakes (Brummel \& Dane, 2013). The mindfulness approach may have a positive impact on communication, problem-solving, organizational performance, and decision processes (Krieger, 2005). Mindfulness increases awareness about work resources and acts as a valuable personal resource that can support proactive performances in work environments (Kroon, Menting, \& Woerkom, 2015). In their research, Barner and Barner (2013) concluded that mindfulness may decrease premature judgments. For this reason, an individual open to new experiences can support transformational learning better in the work place. These studies show that mindfulness is an organizational and individual approach with many benefits. This makes it important to research how to improve and maintain it in the work place. The approach considering faculty trust as a necessary element for school mindfulness is based on the theoretical framework developed by Hoy, Gage and Tarter (2006). According to this approach, the possibility of improving organizational mindfulness is weaker in organizations where there is a culture of long-lasting and reciprocal lack of trust between principals and employees (Becke, 2012). When all the actors trust each other, they try to take mindful actions that would help the others (Smith \& Scarbrough, 2011). In his study, Tingle (2011) concluded that trust facilitates the development of mindfulness and that, similarly, mindfulness would contribute to the creation of a trustworthy environment.

The literature has many studies examining the positive impact of mindfulness on individual, managerial and organizational elements in the work environment. However, the studies on how to develop and strengthen organizational mindfulness are quite limited. For this reason, this study is important in examining the impact of organizational trust on mindfulness as an element that strengthens school mindfulness. Also, it approaches school mindfulness at the sub-dimensional levels of principal mindfulness and faculty mindfulness while approaching organizational trust at the sub-dimensional levels of trust in the school principal, trust in colleagues, and trust in stakeholders. This study therefore offers an overall evaluation by examining the impact of the sub-dimensions of organizational trust on school mindfulness and its sub-dimensions.

\subsection{Research Objectives}

This study examined the impact of the sub-dimensions of organizational trust on school mindfulness, assuming that these sub-dimensions strengthen and develop mindfulness - an individual and organizational approach whereby principals and teachers are conscientious of their duties, open to novelties, committed to resilience, respectful of each other's expertise, that they volunteer to collaborate and remain sensitive to all operations at school.

\subsection{Research Questions}

The purpose of this research was to explore the relationship between school mindfulness and organizational trust. To this end, the answers to the following questions were sought:

1) What are teachers' school mindfulness perceptions?

2) What are teachers' organizational trust perceptions?

3) Is there a significant correlation between school mindfulness and organizational trust?

4) Is organizational trust a better predictor of the school mindfulness?

\section{Methodology}

This part of the study provides information about the research method, sample, data collection tools, and data analysis. The purpose of this research is to explore the relationship between school mindfulness and organizational trust. The aim of the relational research is to investigate bivariate or multiple relationships and predictions between variables (Martin \& Bridgemon, 2012). Relational research design was therefore used, on the assumption that it was appropriate for the purpose of this study.

\subsection{Study Group}

The research population consisted of secondary and high-school teachers in İstanbul province, in the 2018-2019 
academic year. To determine the study group, simple random sampling was applied among the random sampling methods. In simple random sampling, each element meant to be an unbiased representation of the total population has an equal chance of being selected and the unit is selected from the list until the agreed sample size is reached (Büyüköztürk, Çakmak, Akgün, Karadeniz, \& Demirel, 2012). To achieve 0.5 significance and 95 confidence interval, 495 participants selected by the simple random sampling method were included in the analysis (Yamane, 2009). The study sample thus consists of 495 secondary and high school teachers that were working in the province of İstanbul. Of them, 49.3\% $(\mathrm{n}=244)$ were female, and $50.7 \%(\mathrm{n}=251)$ were male, $32.7 \%(\mathrm{n}=162)$ were from secondary schools, and $67.3 \%(\mathrm{n}=333)$ were from high schools. The participants' ages ranged from 24 to 55 . The percentage of those in the age range of 24-30 years was $11.9(n=59)$, those in the age range of 31-40 years was $49.7(n=246)$ and those in the age range of 41 years and above was $38.4(n=190)$. To collect the data of this research, questionnaire forms prepared with a sufficient number of copies were handed out in the academic year 2018-2019.

\subsection{Data-Gathering Tools}

Data were gathered by "Organizational Trust Scale" and "School Mindfulness Scale". The School Mindfulness Scale consisted of 12 items and the following two sub-dimensions: "principal mindfulness" and "faculty mindfulness". The School Mindfulness Scale was used to determine participants' school mindfulness perceptions. The scale was developed by Hoy, Gage and Tarter (2004). Cronbach's $\alpha$ reliability coefficients of the scale were as follows: 0.921 for principal mindfulness and 0.888 for faculty mindfulness. Reliability of the whole scale was found to be as high as Cronbach's Alpha $=0.941$. The second scale used in the research was "Organizational Trust Scale". The Organizational Trust Scale, developed by Y1lmaz (2006), consisted of 22 items and the following three sub-dimensions: "trust in the principal", "trust in colleagues" and "trust in stakeholders". Cronbach's $\alpha$ reliability coefficients of the scale were as follows: 0.892 for trust in the principal, 0.952 for trust in colleagues, and 0.941 for trust in stakeholders. The reliability of the whole scale was found to be as high as Cronbach's Alpha $=0.962$. High scores from the scale showed high levels of participants' organizational trust or school mindfulness perceptions, and low scores from the scale showed low levels of participants' organizational trust or school mindfulness perceptions. The scores were evaluated as $1=$ strongly disagree, $2=$ disagree, $3=$ moderately agree, $4=$ agree and $5=$ strongly agree.

\subsection{Analysis of Data}

The data obtained in the study were analyzed using the SPSS (Statistical Package for Social Sciences) Windows 22.0. Numbers, percentages, averages and standard deviation were used as descriptive statistics methods in data evaluation. Correlation analysis measures the degree of linear relationship between two variables, but does not distinguish between dependent and independent variables. Therefore, correlation analysis is used to determine whether a linear relationship exists. If there is a relationship, then regression analysis is used to quantify the relationship (Richardson, 2015). For this reason, the relation between the variables was first examined by correlation analysis and the predictive degree between dependent and independent variables was then determined by regression analysis. Scale dimensions were evaluated between 1 and 5 points. This range has a width of 4 points, divided into five equal widths. The limits were determined to be 1.00-1.79 "very low", 1.80-2.59 "low", 2.60-3.39 "medium", 3.40-4.19 "high", 4.20-5.00 "very high", and the findings were interpreted (Sümbüloğlu, 1993). Kurtosis and Skewness values were examined to determine whether the study variables show normal distribution.

Table 1. Kurtosis and skewness values

\begin{tabular}{ccc}
\hline & Kurtosis & Skewness \\
\hline School Mindfulness & 0.092 & -0.861 \\
Principal Mindfulness & 0.610 & -1.136 \\
Faculty Mindfulness & 0.195 & -0.798 \\
Organizational Trust & -0.265 & -0.565 \\
Trust in Principal & 0.494 & -1.086 \\
Trust in Colleagues & 0.043 & -0.783 \\
Trust in Stakeholders & -0.400 & -0.487 \\
\hline
\end{tabular}

In the related literature, kurtosis and skewness measures between +1.5 and -1.5 (Tabachnick \& Fidell, 2013), and +2.0 and -2.0 (George \& Mallery, 2010) are considered as normal distribution. T-distribution is used when the 
population variance is unknown. If the whole does not show a normal distribution, non-parametric tests are performed (Field, 2009). As the sampling is adequate according to the law of large numbers and central limit theorem $(\mathrm{N}=495)$, we continued with analyses on the assumption that the distribution was normal (Harwiki, 2013; İnal \& Günay, 1993; Johnson \& Wichern, 2002).

\section{Results}

In this section, the findings related to the research questions given in the introduction are discussed in the order of the research questions.

\subsection{What Are Teachers' School Mindfulness Perceptions?}

Descriptive statistics calculations were made based on the results obtained for the related scale and its sub-dimensions to find an answer for this subgoal of the study. The analysis results for this subgoal are given in Table 2.

Table 2. Results of the descriptive statistics

\begin{tabular}{cccccc}
\hline & $\mathrm{N}$ & $\mathrm{M}$ & $\mathrm{Ss}$ & Min. & Max. \\
\hline School Mindfulness & 495 & 3.885 & 0.847 & 1.000 & 5.000 \\
Principal Mindfulness & 495 & 3.861 & 0.964 & 1.000 & 5.000 \\
Faculty Mindfulness & 495 & 3.910 & 0.835 & 1.000 & 5.000 \\
\hline
\end{tabular}

According to the participants' perceptions about school mindfulness ( $\mathrm{M}=3.885, \mathrm{~S}=.847)$, principal mindfulness $(\mathrm{M}=3.861, \mathrm{~S}=.964)$ and faculty mindfulness $(\mathrm{M}=3.910, \mathrm{~S}=.835)$ were high and positive. When the means of school mindfulness and the sub-dimensions of this variable were considered, a high positive perception was observed.

\subsection{What Are Teachers' Organizational Trust Perceptions?}

Descriptive statistics calculations were made based on the results obtained for the related scale and its sub-dimensions to find an answer for this subgoal of the study. The analysis results for this subgoal are given in Table 3.

Table 3. Results of the descriptive statistics

\begin{tabular}{cccccc}
\hline & $\mathrm{N}$ & $\mathrm{M}$ & $\mathrm{Ss}$ & Min. & Max. \\
\hline Organizational Trust & 495 & 3.962 & 0.776 & 1.320 & 5.000 \\
Trust in Principal & 495 & 3.986 & 0.880 & 1.430 & 5.000 \\
Trust in Colleagues & 495 & 4.010 & 0.852 & 1.250 & 5.000 \\
Trust in Stakeholders & 495 & 3.885 & 0.863 & 1.000 & 5.000 \\
\hline
\end{tabular}

According to the participants' perceptions about organizational trust $(\mathrm{M}=3.962, \mathrm{~S}=0.776)$, trust in the principal $(\mathrm{M}=3.986, \mathrm{~S}=.880)$, trust in colleagues $(\mathrm{M}=4.010, \mathrm{~S}=.852)$, and trust in stakeholders $(\mathrm{M}=3.885, \mathrm{~S}=.863)$ were high and positive. When the means of organizational trust and the sub-dimensions of these variables were considered, a high positive perception was observed.

\subsection{Is There a Significant Correlation Between School Mindfulness and Organizational Trust?}

To find an answer to this subgoal of the study, a correlation analysis was run between the variables in the related scales. The results of the analysis conducted for this subgoal are given in Table 4. 
Table 4. Results of the correlation analysis

\begin{tabular}{ccccccc}
\hline 1. Variable & 1. & 2. & 3. & 4. & 5. & 6. \\
\hline School Mindfulness & 1.000 & & & & & \\
Principal Mindfulness & $.950^{* *}$ & 1.000 & & & & \\
Faculty Mindfulness & $.933^{* *}$ & $.775^{* *}$ & 1.000 & & & \\
Trust in Principal & $.850^{* *}$ & $.878^{* *}$ & $.711^{* *}$ & 1.000 & & \\
Trust in Colleagues & $.797^{* *}$ & $.692^{* *}$ & $.820^{* *}$ & $.746^{* *}$ & 1.000 & \\
Trust in Stakeholders & $.636^{* *}$ & $.528^{* *}$ & $.682^{* *}$ & $.555^{* *}$ & $.706^{* *}$ & 1.000 \\
\hline
\end{tabular}

Note. $\mathrm{p}<0.01$.

Faculty mindfulness and principal mindfulness, two sub-dimensions of the school mindfulness, were significantly and positively correlated with each other $(r=0.775 ; \mathrm{p}=0.000<0.05)$. As expected, school mindfulness was related to principal mindfulness $(\mathrm{r}=0.950 ; \mathrm{p}=.000<0.05)$, while school mindfulness and faculty mindfulness were also related to each other $(r=0.933 ; \mathrm{p}=0.000<0.05)$.

Three sub-dimensions of the organizational trust were significantly correlated with school mindfulness. A significant and positive relationship exists between trust in the principal and school mindfulness $(\mathrm{r}=0.850$; $\mathrm{p}=0.000<0.05)$, trust in colleagues and school mindfulness $(\mathrm{r}=0.797 ; \mathrm{p}=0.000<0.05)$, and trust in stakeholders and school mindfulness $(\mathrm{r}=0.636 ; \mathrm{p}=0.000<0.05)$.

Three sub-dimensions of the organizational trust were significantly correlated with principal mindfulness. There was a positive and significant relationship between principal mindfulness and trust in the principal $(\mathrm{r}=0.878$; $\mathrm{p}=0.000<0.05$ ). We may say, therefore, that the more positive the perception of trust in the principal, the more positive the perception of principal mindfulness. There was also a positive and significant relationship between trust in colleagues and principal mindfulness $(\mathrm{r}=0.692 ; \mathrm{p}=0.000<0.05$, and trust in stakeholders and principal mindfulness $(\mathrm{r}=0.528 ; \mathrm{p}=0.000<0.05)$.

Three sub-dimensions of the organizational trust were significantly correlated with faculty mindfulness. There is a significant and positive relationship between trust in the principal and faculty mindfulness $(\mathrm{r}=0.711$; $\mathrm{p}=0.000<0.05)$, trust in colleagues and faculty mindfulness $(\mathrm{r}=0.820 ; \mathrm{p}=0.000<0.05)$ and trust in stakeholders and faculty mindfulness $(\mathrm{r}=0.682 ; \mathrm{p}=0.000<0.05)$.

\subsection{Is Organizational Trust a Better Predictor of the School Mindfulness?}

To find an answer to this sub-goal of the study, a correlation analysis was run between the variables in the related scales. The results of the analysis conducted for this subgoal are given in Table 5.

Regression analysis was found to be statistically meaningful in determining the relationship between all sub-dimensions of organizational trust and school mindfulness $(\mathrm{F}=591.836 ; \mathrm{p}=0.000<0.05)$. The combined prediction of the organizational trust variables on school mindfulness was very strong $\left(\mathrm{R}^{2}=0.783\right)$. Trust in principal is the strongest predictor of school mindfulness $(\beta=0.559)$. According to this result, we may say that trust in the principal increases school mindfulness. Trust in colleagues also has a meaningful effect on school mindfulness $(\beta=0.315)$. Trust in stakeholders, however, has no effect on school mindfulness $(\beta=0.058)$.

Table 5. Results of the multiple regression analysis

\begin{tabular}{lccccccc}
\hline & Independent Variables & $\beta$ & $\mathrm{t}$ & $\mathrm{p}$ & $\mathrm{F}$ & Model & $\mathrm{R}^{2}$ \\
\hline \multirow{4}{*}{ School Mindfulness } & Trust in Principal & 0.559 & 18.280 & 0.000 & & & \\
& Trust in Colleagues & 0.315 & 7.083 & 0.000 & 591.836 & 0.000 & 0.783 \\
& Trust in Stakeholders & 0.058 & 1.639 & 0.102 & & & \\
\hline \multirow{5}{*}{ Principal Mindfulness } & Trust in Principal & 0.896 & 25.244 & 0.000 & & & \\
& Trust in Colleagues & 0.070 & 1.036 & 0.173 & 562.106 & 0.000 & 0.777 \\
& Trust in Stakeholders & 0.026 & 0.641 & 0.522 & & & \\
\hline \multirow{3}{*}{ Faculty Mindfulness } & Trust in Principal & 0.223 & 6.241 & 0.000 & & & \\
& Trust in Colleagues & 0.559 & 10.800 & 0.000 & 376.655 & 0.000 & 0.697 \\
& Trust in Stakeholders & 0.089 & 2.176 & 0.030 & & & \\
\hline
\end{tabular}

The regression analysis used to determine the relationship between all sub-dimensions of organizational trust and 
principal mindfulness was found to be statistically meaningful $(\mathrm{F}=562.106 ; \mathrm{p}=0.000<0.05)$. When results of regression analysis coefficients were examined, trust in the principal was the sole predictor of principal mindfulness $\left(\mathrm{R}^{2}=0.896\right)$. Trust in colleagues $(\mathrm{p}=0.173>0.05)$ and trust in stakeholders $(\mathrm{p}=0.522>0.05)$, which were other sub-dimensions of organizational trust, had no effect on principal mindfulness.

In addition, regression analysis of the relationship between trust in school principal, trust in colleagues, trust in stakeholders and faculty mindfulness was found to be statistically meaningful $(\mathrm{F}=376.655 \mathrm{p}=0.000<0.05)$. The combined prediction of the organizational trust variable on faculty mindfulness was strong $\left(R^{2}=0.697\right)$. According to the findings, trust in colleagues is the strongest predictor of faculty mindfulness $(\beta=0.559)$, while trust in the principal $(\beta=0.223)$ and trust in stakeholders $(\beta=0.089)$ has a meaningful effect on faculty mindfulness.

\section{Discussion and Conclusions}

School mindfulness consists of principal mindfulness and faculty mindfulness, which are related to each other and provide good content for an organization's general mindfulness. Mindfulness is also important to teacher-student relationships. The teaching support that teachers show to students, the classroom climate, and educational content such as behavior and beliefs can be managed with a more motivational approach thanks to mindfulness. In this respect, teacher mindfulness has a positive impact on in-class teaching activities and the quality of teacher-student relationships (Ong, 2013) and increases performance (Dane \& Brummel, 2013). The study findings concluded that a high level of faculty mindfulness is a positive outcome, considering its positive impact on student-teacher interaction and teacher performance-namely, the benefits that it provides to school.

Mindfulness prepares the ground for principals to better execute managerial acts. Carefully monitoring the ongoing flow, dealing with problems in a timely manner by paying attention to details, and preventing these problems from hindering a school's main operations fall within the competence of management. Mindful principals are sensitive to all operations at school. This type of principal also asks the question: "Who might be the expert to take a decision about this issue?" before automatically taking a decision. Such principals manage the processes based on the answer to this question and take into consideration the success in learning and teaching activities (Gage, 2003). The study concluded that a high level of participant perception regarding principal mindfulness levels matters, and that schools with a high level of mindfulness would probably succeed in student learning and student success (Hoy, 2002). In this respect, the high level of principal and faculty mindfulness concluded by the study is an expected result for school organizations whose ultimate goal is that students learn.

Organizational trust has three sub-dimensions: trust in the principal, trust in colleagues, and trust in stakeholders. Trust in the principal is shaped by a principal's behavior. Trust in colleagues is shaped by teachers' interaction with each other, while trust in stakeholders is a dimension of organizational trust related to students and families (Hoy \& Tschannen-Moran, 1997). Learning and teaching goals of schools require actions to be performed by teachers, principals, students and their families. They are interdependent and affect each other. As these actions are difficult to standardize, they can be performed better in a trusting environment that allows these groups to work together in harmony (Forsyth, Adams \& Hoy, 2010). The level of teachers' interaction with other actors is a function of trust. The higher the trust level, the larger becomes the group a teacher interacts with (Maele \& Houtte, 2011). When teachers do not trust each other in a school, they hesitate to interact with each other and mostly focus on protecting themselves rather than focusing on their common goal. This situation damages collaboration and the desire to participate in decision-making processes, and a school becomes a place of destructive conflicts and increasing distrust. Trust-based environments encourage stronger collaboration, collective actions and constructive conflicts, while reproducing trust. A trusting relationship would likely result in positive behavior as well as student success in school. The trust between teachers and students is a significant facilitator for successful education environments and outcomes (Lee, 2007). Another dimension of trust in a school setting is the trust between teachers and principals. If teachers trust the school principal, they become more creative and innovative in their tasks. This is because they know that they will not be accused or considered inadequate by their principals when they make a mistake, which gives them a higher motivation to learn and to teach (Chughtai \& Buckley, 2009). In consequence, we understand that trust is an element with social value and contributes to a school. Schools need trustworthy environments if they are to make a positive contribution.

Trust is significant, as it allows many different actors to work in a constructive relationship. The high level of organizational trust and its sub-dimensions concluded by this study are therefore not surprising. We see similar results when we examine the research studies on organizational trust in the related literature. The research conducted by Bökeoğlu and Yılmaz (2008) about primary school teachers' perception of organization trust concluded that teachers trust their principals most, secondly other teachers working in the same school, and lastly stakeholders. Another study conducted by Celep and Polat (2008) in secondary schools concluded that participant 
teachers' organizational trust perception is high. These data are similar to the conclusion reached in this study: that organizational trust and the level of trust in the principal, level of trust in colleagues, and level of trust in stakeholders sub-dimensions are high.

Faculty mindfulness defends the culture of trust and openness which allows for more flexibility in changing rules and procedures, an effective communication rather than an authoritarian order, allowing its members to raise their voice to ask questions (Ong, 2013). Mindfulness requires recognizing people when it comes to their field of expertise. It is easier to benefit from people's knowledge when we trust their expertise. In this respect, trust makes it easier to benefit from people's expertise and strengthens social interactions required by collective mindfulness in order to solve problems effectively (Blomqvist, 2014). Cooperation is more successful when a school principal gains the trust of teachers and students. Thanks to trust, beneficial social relationships develop between all parties in the school. These relationships facilitate problem-solving processes and innovative initiatives (Blase \& Blase, 2003; Buffum, 2008). Individuals also become open to mutual interaction and sharing information becomes easier (Hoy, Smith, \& Sweetland, 2002; Tschannen-Moran, 2004). Different areas of expertise and the necessity of collaborating among these areas make trust a unifying power (Mayerson, 2010).

In summary, it can be said that trust can increase the relationships within the organization and produce the desired performance results (Manimegalai \& Baral, 2017). The school principal plays a key role in the formation of such a school culture (Anderson, Kochan, Kensler, \& Reames, 2018). If the manager trusts the competence of the employees, this affects the ability of the employees positively. In mindful organizations, managers rely on the competence of their employees and focus on encouragement rather than mistakes (Reb \& Atkins, 2015). The affirmative impacts of organizational mindfulness are greater in working groups that trust their leaders (Sutcliffe, Vogus, \& Dane, 2016). The solution of some problems requires knowledge of different specialties. In this case, many people must work together. Even if their areas of expertise differ, trust among employees supports their collaboration (Blomqvist, 2013). Constructive relationships built by people with very different qualities make a contribution to faculty mindfulness. For this reason, the conclusion that trusts in the principal and in colleagues' increases faculty mindfulness is an expected result of this study.

Likewise, coherent actions among teachers and principals may provide a positive contribution to faculty mindfulness by increasing the potential for adapting to fast-changing conditions, dealing with difficulties, and developing new approaches. According to the research findings, a positive and high correlation exists between faculty mindfulness and trust in the principal and trust in colleagues (sub-dimensions of organizational trust). Additionally, there is a high and positive correlation between organizational trust and its sub-dimensions, which are trust in the principal, trust in colleagues, and trust in stakeholders. The research also concluded that principals' mindfulness is mostly affected by the trust placed in principals. Because mindful school leadership is reinforced by trust in the principal (Well, 2015), principals may develop mindfulness by ensuring that teachers feel secure enough to be innovative and take reasonable risks (Hoy, Gage, \& Tarter, 2006). Exchanging opinions considering others' areas of expertise, creating an environment of communication in which individuals can easily raise their issues, and having an innovative approach improve principal mindfulness. However, it requires principals to mutually and openly interact with other actors. Having such an interaction with other actors and being someone that others can easily contact will become easier when the principal is trusted. According to the research findings, the trust in the principal has a significant effect on both school and principal mindfulness. Other results of the study show that principal mindfulness is also affected by the trust that teachers have in each other. Interpersonal trust enables effective team work as it facilitates collaboration and communication. This, as a result, may contribute to principal mindfulness. The frequency of teachers' interaction with other actors at school is a function of trust. The higher the trust level, the larger becomes the group a teacher interacts with (Houtte \& Maele, 2011). For this reason, the positive contributions that trust makes to organizational behaviors may help to improve faculty mindfulness. In this respect, the research data reveal an expected result: faculty mindfulness is affected respectively by trust in colleagues, trust in the principal, and trust in stakeholders sub-dimensions. Trust-based environments encourage stronger collaboration, collective actions and constructive conflicts while reproducing trust.

\section{References}

Arendt, J., Verdorfer, A, P., \& Kugler, K. (2019). Mindfulness and leadership: communication as a behavioral correlate of leader mindfulness and its effect on follower satisfaction. Frontiers in Psychology, 10, 1-16. https://doi.org/10.3389/fpsyg.2019.00667

Aviles, P. R., \& Dent, E. B. (2015). The role of mindfulness in leading organizational transformation: A systematic review. The Journal of Applied Management and Entrepreneurship, 20(3), 31-55. 
https://doi.org/10.9774/GLEAF.3709.2015.ju.00005

Barner, R., \& Barner, C. (2013). The role of mindfulness in fostering transformational learning in work settings. Advances in Positive Organizational Psychology, 1, 189-210. https://doi.org/10.1108/s2046-410x(2013)0000001011

Bauch, P. (2014). Catholic Schools in the Public Interest: Past, Present, and Future Directions. Information Age Publishing.

Becke, G. (2012). Organizational Mindfulness in Permanent Change-Promoting Social Sustainability at Organizational Level. Artec-paper Nr. 18. https://doi.org/10.1007/978-3-642-38694-7_4

Bjurström, E. (2012). Minding the contexts of mindfulness in quality management. International Journal of Quality \& Reliability M anagement, 29(6), 699-713. https://doi.org/10.1108/02656711211245674.

Blase, J., \& Blasé, J. (2003). The phenomenology of principal mistreatment: teachers' perspectives. Journal of Educational Administration, 41(4), 367-422. https://doi.org/10.1108/09578230310481630

Blomqvist, K. (2013). Building sustainable organizational Trust in radical changes-The interplay of organizational trust and mindfulness. In G. Becke (Ed.), Mindful Change in Times of Permanent Reorganization: Organizational, Institutional and Sustainability Perspectives (pp. 131-146). Bremen: Springer Science \& Business Media. https://doi.org/10.1007/978-3-642-38694-7_8

Bökeoğlu, Ö. Ç., \& Yılmaz, K. (2008). İlköğretim okullarında örgütsel güven hakkında öğretmen görüşleri. Educational Administration: Theory and Practice, 54, 221-233

Brief, A., \& Weiss, H. (2002). Organizational behavior: Affect in the workplace. Annual Review Psycholgy, 52, 279-307. https://doi.org/10.1146/annurev.psych.53.100901.135156

Büyüköztürk, Ş., Çakmak E., Akgün, Ö., Karadeniz, Ş., \& Demirel, F. (2012). Bilimsel araştırma yöntemleri. İstanbul: Kalıtım Kitabevi.

Caldwell, C., \& Clapham, S. (2003). Organizational trustworthiness: An International Perspective. Journal of Business Ethics, 47(4), 349-364. https://doi.org/10.1023/A:1027370104302

Chughtai, A., \& Buckley, F. (2009). Linking trust in the principal to school outcomes: The mediating role of organizational identification and work engagement. International Journal of Educational Management, 23(7), 574-589. https://doi.org/10.1108/09513540910990816

Clep, P., \& Polat, S. (2008). Ortaöğretim öğretmenlerinin örgütsel adalet, örgütsel güven, örgütsel vatandaşlık davranışlarına ilişkin algıları. Educational Administration: Theory and Practice, 54, 307-331.

Dane, E. (2011). Paying attention to mindfulness and its effects on task performance in the workplace. Journal of Management, 37(4), 997-1018. https://doi.org/10.1177/0149206310367948

Dane, E., \& Brummel, B. (2013). Examining workplace mindfulness and its relations to job performance and turnover intention. Human relations, 67(1), 105-128. https://doi.org/10.1177/0018726713487753

Fiol, C. M., \& O'Connor, E. (2003). Waking up! Mindfulness in the face of bandwagons. The Academy of Management Review, 28(1), 54-70. https://doi.org/10.2307/30040689

Forsyth, P. B., Adams, C. M., \& Hoy, W. K. (2011). Collective trust: Why schools can't improve without it. New York: Teachers College Press.

Gage, C. Q., (2003). The meaning and measure of school mindfulness: An exploratory analysis (Unpublished $\mathrm{Ph}$.D. thesis). The Ohio State University.

Gebauer, A. (2012). Mindful organizing as a paradigm to develop managers. Journal of Management Education, 37(2), 203-228. https://doi.org/10.1177/1052562912458573

George, D., \& Mallery, P. (2010). SPSS for Windows step by step: A simple guide and reference. Boston: Pearson.

Giluk, T. (2009). Mindfulness, big five personality and affect: A meta-analysis. Personality and Individual Diferences, 47(8), 805-811. https://doi.org/10.1016/j.paid.2009.06.026

Ginn, C. W. (2014). The relationship between organizational trust and perception of mindfulness: An exploration of high school athletic departments (Unpublished Ph.D. thesis). The University of Alabama, Tuscaloosa, ABD.

Glomb, T. M., Duffy M. K., Bono, J. E., \& Yang, T. (2011). Mindfulness at work. Research in Personnel and 
Human Resources Management, 30, 115-157. https://doi.org/10.1108/S0742-7301(2011)0000030005

Harwiki, W. (2013). The influence of servant leadership on organizational culture, organizational commitment, organizational citizenship behavior, and employees' performance study of outstanding cooperatives in East Java Province, Indonesia. Journal of Economics and Behavioral Studies, 5(12), 876-885. https://doi.org/10.22610/jebs.v5i12.460

Hoy, W. (2002). An analysis of enabling and mindful school structures: Some theoretical, research and practical considerations. Journal of Educational Administration, 41(1), 87-109. https://doi.org/10.1108/09578230310457457

Hoy, W. K., Gage, C. Q., \& Tarter, C. J. 2006. School mindfulness and faculty trust: Necessary conditions for each other? Educational Administration Quarterly, 42(2), 236-255. https://doi.org/10.1177/0013161x04273844

Hyland, P., Lee, R. A., \& Mills, M. J. (2015). Mindfulness at work: A new approach to improving individual and organizational performance. Industrial and Organizational Psychology, 8(4), 576-602. https://doi.org/10.1017/iop.2015.41

İnal, H. C., \& Günay, S. (1993). Olasllk ve matematiksel istatistik. Ankara: Hacettepe Üniversitesi Yayınları.

Johnson, R. A., \& Wichern, D. W. (2002). Applied multivariate statistical analysis. USA: Prentice Hall.

Kearney, S. W., Kelsey, C., \& Herrington, D. (2013). Mindful leaders in highly effective schools: A mixed-method application of Hoy's M-scale. Educational Management Administration \& Leadership, 41(3), 316-335. https://doi.org/10.1177/1741143212474802

Krieger, J. L., (2005). Shared mindfulness in cockpit crisis situations: An exploratory analysis. Journal of Business Communication, 42(2), 135-167. https://doi.org/10.1177/0021943605274726

Kroon, B., Menting, C., \& Woerkon, M. (2015). Why mindfulness sustains performance: The role of personal and job resources. Industrial and Organizational Psychology, 8(4), 638-642. https://doi.org/10.1017/iop.2015.92.

Langer, E. J. (1992). Matters of mind: Mindfulness/Mindlessness in perspective. Consciousness and Cognition, l(3), 289-305. https://doi.org/10.1016/1053-8100(92)90066-J

Langer, E. J., \& Moldoveonu, M. (2000). The construct of mindfulness. The Journal of Social Issues, 56(1), 1-9. https://doi.org/10.1007/978-3-319-30782-4_2

Langer, E., \& Ngnoumen, C. (2017). In Mindfulness. D. S. Dunn (Ed.), Positive Psychology (pp. 17-65). London: Routledge Issue. https://doi.org/10.4324/9781315106304-7

Lee, S. (2007). The relations between the student-teacher trust relationship and school success in the case of Korean middle schools. Educational Studies, 33(2), 209-216, https://doi.org/10.1080/03055690601068477

Lingtao Y., \& Mary, Z. (2017). Introducing team mindfulness and considering its safeguard role against conflict transformation and social undermining. Academy of Management Journal, 61(1). https://doi.org/10.5465/amj.2016.0094

Long, E., \& Christian, E. (2015). Mindfulness buffers retaliatory responses to injustice: A regulatory. Approach Journal of Applied Psychology, 100(5), 1409-1422. https://doi.org/10.1037/ap10000019

Maele, D., \& Houtte, M. (2011). The quality of school life: Teacher-student trust relationships and the organizational school context. Social Indicators Research, 100, 85-100. https://doi.org/10.1007/s11205-010-9605-8

Malinowski, P., \& Lim, H. J. (2015). Mindfulness at work: Positive affect, hope, and optimism mediate the relationship between dispositional mindfulness, work engagement, and well-being. Mindfulness, 6, 1250-1262. https://doi.org/10.1007/s12671-015-0388-5

Mayerson, D. (2010). The relationship between school climate, trust, enabling structures, and perceived school effectiveness (Unpublished Ph.D. thesis). St. John's University, Canada.

Mu, E., \& Butler, B, S. (2012). The assessment of organizational mindfulness processes for the effective assimilation of it innovations. Journal of Decision Systems, 18(1), 27-51. https://doi.org/10.3166/jds.18.27-51

Ndubisi, N. (2012). Mindfulness, quality and reliability in small and large firms. International Journal of Quality \& Reliability Management, 29(6), 600-606. https://doi.org/10.3166/jds.18.27-51 
Ndubisi, N., \& Al-Shuridah, O. (2019). Organizational mindfulness, mindful organizing, and environmental and resource sustainability. Business Strategy and the Environment, 28(1), 436-446. https://doi.org/10.1002/bse.2219

Reb, J., Narayanan, J., \& Chaturvedi, S. (2004). Leading mindfully: Two studies of the influence of supervisor trait mindfulness on employee wellbeing and performance. Singapore Management University.

Roche, M., Haar, J., \& Fred, L. (2014). The Role of Mindfulness and Psychological Capital on the Well-Being of Leaders. Journal of Occupational Health Psychology, 19(4), 476-489. https://doi.org/10.1037/e528472014-021

Scarbrough, C. S. (2005). Aspects of School Mindfulness and Dimensions of Faculty Trust: Social Processes in Elementary Schools (Unpublished doctoral thesis). The University of Texas at San Antonio.

Schultz, P., Ryan R., Niemiec, C., Legate, N., \& Williams, G. (2014). Mindfulness, Work Climate, and Psychological Need Satisfaction in Employee Well-being. Mindfulness, 6(5), 971-985. https://doi.org/10.1007/s12671-014-0338-7

Shapiro, S., Wang, M. \& Peltason, E. (2015). What is mindfulness why should organizations care about it? In J. Reb, \& P. W. B. Atkin (Eds.), Mindfulness in organizations: Foundations, research, and applications (pp. 17-44). Cambridge: Cambridge University Press. https://doi.org/10.1017/CBO9781107587793.004

Smith, K., \& Larimer, C. (2004). A Mixed Relationship: Bureaucracy and School Performance. Public Administration Review, 64(6), 728-736. https://doi.org/10.1111/j.1540-6210.2004.00419.x

Smith, P., \& Scarbrough, C. S. (2011). Mindful schools as high-reliability organizations: the effect of trust on organizational mindfulness. In M. DiPaola, \& P. B. Forsyth (Eds.), Leading research in educational administration: A festschrift for Wayne K. Hoy (pp. 16-44). North Carolina: Information Age Publishing.

Tabachnick, B. G., \& Fidell, L. S. (2013). Using multivariate statistics. Boston: Pearson.

Taesdale, J., \& Chaskalson, M. (2011). How does mindfulness transform suffering? I: The nature and origins of dukkha. Contemporary Buddhism, 12(1), 89-102. https://doi.org/10.1080/14639947.2011.564824

Tingle, J. K. (2011). The relationship between organizational trust and mindfulness: an exploration of NCAA Division III athletic departments (Unpublished Ph.D. thesis). The University of Texas at San Antonio, San Antonio, ABD.

Tschannen-Moran, M., \& Hoy, W. K. (1997). Trust in schools: A conceptual and empirical analysis. Journal of Educational Administration, 36(4), 334-352. https://doi.org/10.1108/09578239810211518

Valentine, S., Godkin, S., \& Varca, P. (2009). Role conflict, mindfulness, and organizational ethics in an education-based healthcare institution. Journal of Business Ethics, 94(3), 455-469. https://doi.org/10.1007/s10551-009-0276-9

Weick, K. E., \& Sutcliffe, Kathleen M. 2011. Managing the unexpected: resilient performance in an age of uncertainty. New Jersey: John Wiley \& Sons.

Weick, K., \& Sutcliffe, K. (2006). Mindfulness and the quality of organizational attention. Organization Science, 17(4), 417-526. https://doi.org/10.1287/orsc.1060.0196

Wells, C. M. (2015). Conceptualizing Mindful Leadership in Schools: How the Practice of Mindfulness Informs the Practice of Leading. NCPEA Education Leadership Review of Doctoral Research, 2(1), 1-23.

Willomson, B. W. (2010). Organizational health and mindfulness as predictors of school effectiveness: Using the balanced scorecard (Unpublished Ph.D. thesis). The University of Alabama, Tuscaloosa, ABD.

Wolf, M., Vykoukal, J., \& Beck, R. (2009). Innovating Mindfully with Service-Oriented Grids-The Role of Organizational Mindfulness in Turbulent Environments. Association for Information Systems AIS Electronic Library, 6, 1-15.

Yamane, T. (2009). Temel örnekleme yönetemleri. İstanbul: Literatür Yayınc1lık.

Zand, D. E. (1997). The leadership triad: Knowledge, trust, and power. New York: Oxford University Press. 


\section{Copyrights}

Copyright for this article is retained by the author(s), with first publication rights granted to the journal.

This is an open-access article distributed under the terms and conditions of the Creative Commons Attribution license (http://creativecommons.org/licenses/by/4.0/). 